\title{
Proposição de um modelo para a gestão da demanda: um estudo entre os elos atacadista e fornecedores de produtos de mercearia básica
}

\section{A proposed framework for demand management: a study involving wholesalers and suppliers of grocery products}

\author{
Daniela de Castro Melo' \\ Rosane Lúcia Chicarelli Alcântara²
}

\begin{abstract}
Resumo: A gestão da demanda é um tema emergente no campo de conhecimento da gestão da cadeia de suprimentos. O que se busca com a gestão da demanda é a rápida e adequada integração das necessidades originadas do mercado na direção dos fornecedores, de modo a balancear e alinhar estrategicamente a demanda com a capacidade operacional ao longo da cadeia de suprimentos. Esse alinhamento da demanda na cadeia de suprimentos enfrenta dificuldades provocando ineficiência no atendimento a clientes, redução do giro de estoque e alto índice de obsolescência agravada pela grande diversidade de produtos. O objetivo deste estudo foi desenvolver um modelo para a gestão da demanda na cadeia de suprimentos de produtos de mercearia básica considerando os elos fornecedor e atacadista distribuidor. Para tal, realizou-se uma pesquisa qualitativa por meio de um estudo de caso na empresa atacadista Martins e em nove fornecedores desta empresa. A pesquisa revelou que o processo de implantação da gestão da demanda pode ser dividido em três fases: 1) alinhamento conjunto das diretrizes estratégicas das empresas; 2) formulação do plano de negócios; e 3) execução e acompanhamento do plano de negócios. Além disso, este processo apresenta três elementos que o permeiam: envolvimento da alta gerência, interações inter e intraempresas e resultados da gestão da demanda. Estes resultados compreendem o aumento da rentabilidade por meio da melhoria da eficiência e eficácia, como também o compartilhamento de conhecimento e aprendizado pelas empresas.
\end{abstract}

Palavras-chave: Gestão da demanda. Gestão da cadeia de suprimentos. Atacadista. Produtos de mercearia básica.

\begin{abstract}
Demand management is an emerging topic in supply chain management. It is focused on a fast and adequate integration of supplier needs in order to balance and strategically align demand with operational capability in the supply chain. The demand alignment in the supply chain may pose some problems leading to inefficient customer service, poor stock rotation, and high obsolescence rate aggravated by the wide diversity of products. The objective of this study was to develop a framework for demand management in the supply chain of grocery products considering the dyadic relationship between the supplier and wholesaler. Therefore, a case study was conducted in the wholesale company Martins and nine of its suppliers. The research revealed that the demand management implementation process can be divided into three phases: 1) joint alignment of strategic policies, 2) formulation of business plan, and 3) implementation and monitoring of the business plan. Moreover, this process consists of three elements: top management involvement, inter and intra-firm interactions, and benefits of demand management. The benefits include profitability increase by improving efficiency and effectiveness, as well as knowledge sharing and learning.
\end{abstract}

Keywords: Demand management. Supply chain management. Wholesale. Grocery industry.

\section{Introdução}

A gestão da demanda é um tema emergente no campo de conhecimento da gestão da cadeia de suprimentos. O que se busca com a gestão da demanda é a rápida e adequada integração das necessidades originadas do mercado na direção dos fornecedores, de modo a balancear e alinhar estrategicamente a demanda

com a capacidade operacional ao longo da cadeia de suprimentos. Alguns autores destacam a necessidade de pesquisas sobre a gestão da demanda (ADEBANJO, 2009; KAIPIA; KORHONEN; HARTIALA, 2006; SIMATUPANG; SRIDHARAN, 2002; TAYLOR, 2006; TAYLOR; FEARNE, 2006) após verificarem,

\footnotetext{
${ }^{1}$ Universidade Federal de Uberlândia - UFU, Av. João Naves de Ávila, 2121, CEP 38400- 902, Uberlândia, MG, Brasil, e-mail: daniela_c_melo@yahoo.com.br

${ }^{2}$ Universidade Federal de São Carlos - UFSCar, Rod. Washington Luis, Km 235, CEP 13560-000, São Carlos, SP, Brasil, e-mail: rosane@dep.ufscar.br
} 
por meio de pesquisas empíricas, que a falta de alinhamento entre oferta e demanda era um problema crônico e caro em várias cadeias de suprimentos com perdas devido a desperdícios, à falta ou ao excesso de estoques e a baixas margens de lucro. Assim, o atendimento das necessidades dos consumidores deve ser sincronizado ao longo da cadeia de suprimentos.

Constata-se também que há pouca informação disponível sobre a gestão da demanda em cadeias de suprimentos (ADEBANJO, 2009; MELO; ALCÂNTARA, 2010; TAYLOR, 2006; TAYLOR; FEARNE, 2006; TROQUE, 2003). Segundo Hilletofth, Ericsson e Christopher (2009), a gestão da demanda é uma forma das empresas alcançarem um benefício substancial focando o cliente e ressaltam que a aplicação da gestão da demanda é ainda muito recente, necessitando de mais pesquisas que abordem o tema.

As abordagens identificadas na literatura (CROXTON et al., 2008; ESPER et al., 2010; HILLETOFTH; ERICSSON; CHRISTOPHER, 2009; JÜTTNER; CHRISTOPHER; BAKER, 2007; MENTZER; MOON, 2005; VOLUNTARY..., 2010) não exploraram empiricamente como as empresas podem implantar a gestão da demanda.

Croxton et al. (2008) detalharam, de forma conceitual, o processo de gestão da demanda sob a perspectiva da gestão da cadeia de suprimentos, propondo subprocessos estratégicos e operacionais para sua implantação. Porém não foi identificado nenhum trabalho empírico publicado que relate a implantação e aplicabilidade nas empresas deste modelo proposto pelos autores. Além disso, os autores ressaltam a necessidade de definição de uma estrutura de indicadores de desempenho para avaliar o processo de gestão da demanda, mas se limitam a apontar apenas dois indicadores: os erros de previsão e a utilização da capacidade.

Além disso, Stock, Boyer e Harmon (2010) levantam a necessidade de estabelecer modelos e estruturas para identificar o que diferencia as empresas que se destacam na gestão da cadeia de suprimentos daquelas que não são bem sucedidas.

Diante da necessidade de trabalhos que explorem a gestão da demanda levantada por diversos autores (ADEBANJO, 2009; KAIPIA; KORHONEN; HARTIALA, 2006; MENTZER; MOON, 2005; SIMATUPANG; SRIDHARAN, 2002; TAYLOR, 2006; TAYLOR; FEARNE, 2006; TROQUE, 2003), o objetivo geral deste trabalho é desenvolver um modelo para a gestão da demanda na cadeia de suprimentos de produtos de mercearia básica envolvendo os elos atacadista distribuidor e fornecedor. Este modelo visa auxiliar as empresas dessa cadeia a identificar as variáveis envolvidas para o desenvolvimento de seus negócios em conjunto para melhor atender à demanda e, assim, possibilitar, com a sua adequada implantação, o aumento da rentabilidade.
A importância e a possível contribuição desta pesquisa estão justificadas pelo fato da gestão da demanda sob a perspectiva da gestão da cadeia de suprimentos ser um conceito novo, ainda não consolidado, que carece de mais estudos e definições. Além disso, destaca-se o fato de a pesquisa trabalhar com casos práticos que abordam a sua implantação e gestão, apresentando e discutindo as experiências de empresas. Com isso, espera-se contribuir para uma melhor compreensão e visão mais ampla da gestão da demanda que aponte caminhos a serem adotados pelas organizações para a superação dos desafios atuais de conciliar as necessidades dos clientes e as capacidades da cadeia de suprimentos. Por fim, os resultados deste trabalho podem despertar o interesse de outros setores industriais a desenvolverem estratégias de gestão da demanda ou servir de benckmarking para a implantação da gestão da demanda com parceiros estratégicos na cadeia de suprimentos.

$\mathrm{O}$ artigo está estruturado em quatro partes. Inicialmente, no referencial teórico, são discutidos os requisitos para a gestão da demanda na cadeia de suprimentos. Na sequência, é apresentado o método de pesquisa e, em seguida, os seus resultados. Por fim, são apresentadas as conclusões.

\section{A gestão da demanda na cadeia de suprimentos}

Os conceitos e objetivos da gestão da demanda discutidos por diversos autores (CROXTON et al., 2008; HILLETOFTH; ERICSSON, 2007; HILLETOFTH; ERICSSON; CHRISTOPHER, 2009; JÜTTNER; CHRISTOPHER; BAKER, 2007; MENTZER et al., 2007; MENTZER; MOON, 2005; PIRES, 2009; RAINBIRD, 2004; VOLLMANN et al., 2004; WALTERS, 2006; WALTERS; RAINBIRD, 2004) pressupõem que a gestão da demanda envolve a criação de sinergias entre a gestão de operação e de marketing com o objetivo de compreender o mercado e desenvolver ações sincronizadas com a estratégia da empresa, capacidade produtiva e atendimento das necessidades do consumidor final.

A revisão da literatura permitiu identificar os requisitos para a gestão da demanda na cadeia de suprimentos que podem ser visualizados na Figura 1, cada um deles será discutido a seguir.

\section{- Cadeia de suprimentos colaborativa}

Segundo Mentzer et al. (2001), a orientação para a cadeia de suprimentos é um pré-requisito para a gestão da cadeia de suprimentos que consiste no desenvolvimento de esforços colaborativos intra e interempresas. Estes esforços representam os elementos da colaboração que, conforme Chen, Daugherty e Roath (2009), Fawcett, Magnan e McCarter (2008), Holweg et al. (2005), Horvath (2001), Mentzer, Fonghin e Golicic (2000), Min et al. (2005), Sabath e Fontanella (2002), Simatupang e Sridharan (2002, 


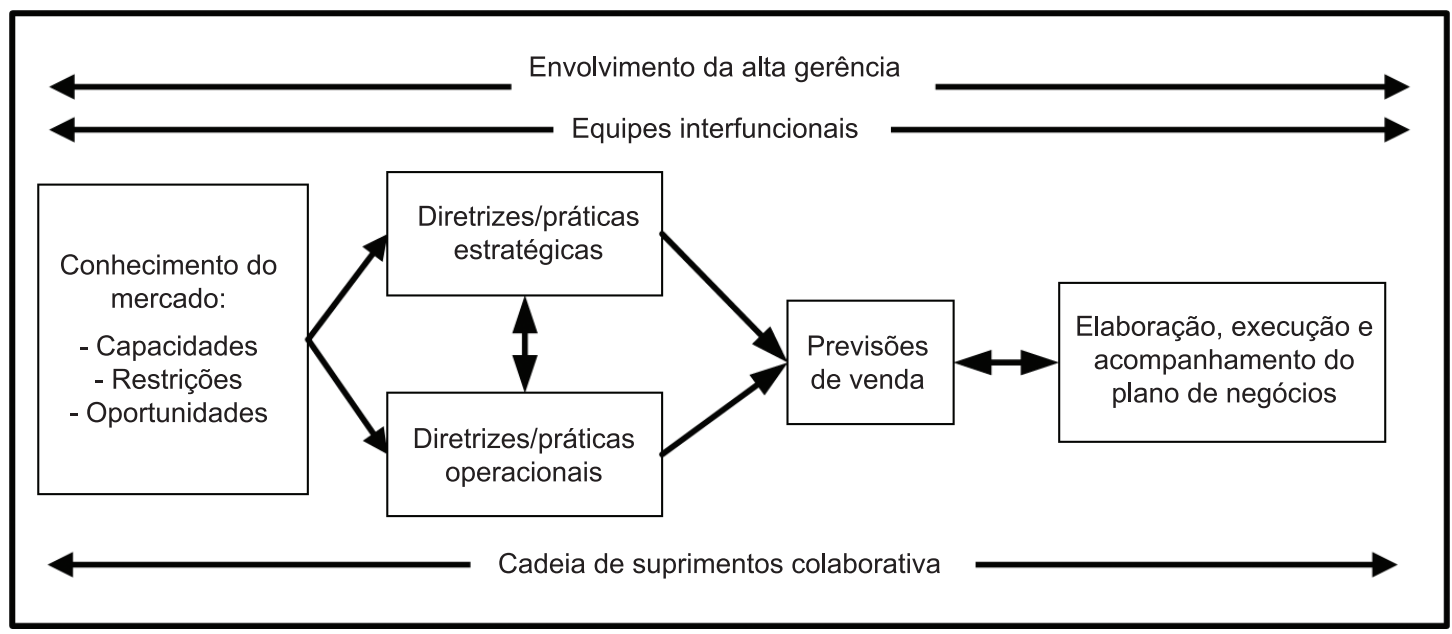

Figura 1. Requisitos para a gestão da demanda na cadeia de suprimentos. Fonte: Elaborado pelas autoras.

2004), Stank, Keller e Daugherty (2001) e Vieira, Yoshizaki e Ho (2009), são: compartilhamento de informações; planejamento e execução de ações conjuntas; compartilhamento de riscos, custos e ganhos; desenvolvimento de relacionamento interno e externo à organização; investimentos financeiros e não financeiros; definição e acompanhamento de indicadores de desempenho.

- Conhecimento das capacidades, restrições e oportunidades do mercado

Para a implantação da gestão da demanda, é necessário compreender o mercado (CROXTON et al., 2008; ESPER et al., 2010; HILLETOFTH; ERICSSON; CHRISTOPHER, 2009; JÜTTNER; CHRISTOPHER; BAKER, 2007; MENTZER; MOON, 2005; RAINBIRD, 2004) por meio da análise das capacidades, restrições, oportunidades dos ambientes interno e externo à empresa. $\mathrm{O}$ conhecimento do mercado interno e externo à empresa ditará as diretrizes e práticas estratégicas e operacionais da organização.

- Conhecimento das diretrizes/práticas estratégicas e operacionais das empresas

Envolve compartilhar informações estratégicas e operacionais entre as empresas para conhecer as dificuldades e potencialidades do parceiro (VIEIRA; YOSHIZAKI; HO, 2009) e gerar informações de previsões de demanda e suprimentos (informações de capacidade, iniciativas, estratégias dos fornecedores, tecnologia, tendências do setor, nível de estoque, transporte, opções de armazenamento) (ESPER et al., 2010). Além disso, ter acesso à intenção estratégica do parceiro permite o conhecimento do objetivo de crescimento, obtenção de participação de mercado, melhoria dos serviços oferecidos (MIN et al., 2005).

- Desenvolvimento de equipes interfuncionais

O processo de gestão da demanda envolve uma equipe interfuncional composta por integrantes de diversos níveis e setores da organização, bem como representantes estratégicos da cadeia de suprimentos (fornecedores e clientes) (CHEN; DAUGHERTY; ROATH, 2009; CROXTON et al., 2008; HILLETOFTH; ERICSSON; CHRISTOPHER, 2009; JÜTTNER; CHRISTOPHER; BAKER, 2007; MENTZER et al., 2007; VOLLMANN et al., 2004). Esta equipe interfuncional deve ter uma ampla compreensão do mercado, das diretrizes e práticas estratégicas e operacionais da organização (CROXTON et al., 2008; ESPER et al., 2010; HILLETOFTH; ERICSSON; CHRISTOPHER, 2009; MENTZER et al., 2007).

\section{- Desenvolvimento de previsões de vendas}

A previsão de vendas é a projeção para o futuro da demanda esperada (MENTZER et al., 2007) e tem por objetivo acuracidade (MENTZER et al., 2007; TAYLOR; FEARNE, 2006). Segundo Croxton et al. (2008), para desenvolver as previsões, é necessário determinar o nível de detalhamento, abrangência da previsão, identificar as fontes de informação e definir o método de previsão, podendo envolver equipes interfuncionais interna e externa à empresa.

- Elaboração, execução e acompanhamento do plano de negócios

Constata-se que as empresas podem implantar diferentes níveis das iniciativas de S\&OP (Planejamento de Vendas e Operações) (GRIMSON; PYKE, 2007; LAPIDE, 2005), de CPFR (Planejamento, Previsão e Reposição Colaborativos) (DANESE, 2007; LARSEN; THERNOE; ANDRESEN, 2003; SEIFERT, 2003) e de VMI (Gerenciamento do Estoque pelo Fornecedor) (CLAASSEN; VAN WEELE; VAN RAAIJ, 2008; ELVANDER; SARPOLA; MATTSSON, 2007) na gestão da demanda.

Min et al. (2005) citam como uma das consequências da colaboração na cadeia de suprimentos, à medida que o relacionamento entre os parceiros melhora, o 
desenvolvimento de um plano de negócios conjunto que será executado pelas equipes interfuncionais de cada empresa. No contexto da gestão da demanda, Mentzer et al. (2007) conceituam "plano" como um conjunto de ações gerenciais específicas a serem tomadas para alcançar ou exceder as previsões de vendas. Diante das condições econômicas, da concorrência, dos planos de Marketing, Vendas, Produção e Logística, a projeção da demanda futura é realizada. Desta base, o plano de negócios é desenvolvido e este processo é iterativo, pois, se o plano de negócios resultante não estiver alinhado com as necessidades e objetivos financeiros da empresa, retorna-se na previsão de vendas e examina-se que esforços adicionais podem ser realizados para alcançar o plano de negócios. Garantindo, portanto, um plano baseado nas realidades financeiras e de mercado que a empresa enfrenta, nas capacidades logísticas e de produção, e da cadeia de suprimentos (MENTZER et al., 2007).

No CPFR, as empresas parceiras irão desenvolver um plano de negócio conjunto para identificar os eventos significantes que afetam o fornecimento e a demanda, estabelecendo as previsões de vendas e de ressuprimento (VOLUNTARY..., 2004). O S\&OP envolve a integração dos planos de marketing com a gestão da cadeia de suprimentos para dar suporte ao processo de planejamento anual de negócios (ASSOCIATION..., 2009). VICS (VOLUNTARY..., 2010) propõe desenvolver um plano de negócio integrado em que atividades de $\mathrm{S} \& \mathrm{OP}$ como, por exemplo, alinhamento interno, ciclo de revisão mensal, horizonte de planejamento, envolvimento de executivos com poder de decisão, detalhamento do plano de vendas e de marketing são incorporados ao CPFR.

Segundo Esper et al. (2010), a aplicação do conhecimento dos ambientes interno e externos e das previsões de demanda e de capacidade toma forma por meio dos planos de demanda (4Ps de marketing: preço, praça, promoção e produto) e de operações (produção, estoque, compras e distribuição). Para Croxton et al. (2008), a execução de um plano único tem por objetivo equilibrar as necessidades e os custos da Manufatura, Logística, Vendas e fornecedores para atender a uma demanda antecipada.

Desta forma, constata-se a utilização dos termos "plano de negócio conjunto" (BARRATT; OLIVEIRA, 2001; MIN et al., 2005; VOLUNTARY..., 2004), "plano de negócio integrado" VICS (VOLUNTARY..., 2010), "plano de negócio" (MENTZER et al., 2007), "plano de marketing e gestão da cadeia de suprimentos" (ASSOCIATION..., 2009), "plano de demanda, suprimentos e finanças" (WALLACE, 2004), "plano de demanda e operações" (ESPER et al., 2010), "plano único" (CROXTON et al., 2008) para designar um conjunto de ações desenvolvidas por parceiros na cadeia de suprimentos. Estas ações englobam a sincronização da gestão de marketing e de operações para melhor atender à demanda; as ações devem estar alinhadas com o direcionamento estratégico das empresas. Neste mesmo sentido, esta pesquisa utiliza o termo "plano de negócio" buscando simplificação e padronização.

Por fim, o processo de colaboração deve ser formalizado detalhando as métricas de desempenho (MIN et al., 2005) que envolvem direcionamentos específicos em custos, produtividade e metas de ganhos. No processo de gestão da demanda, as equipes interfuncionais desenvolvem uma estrutura de indicadores para medir e monitorar o processo e estabelecem os objetivos para a melhoria de desempenho (CROXTON et al., 2008).

\section{- Envolvimento da alta gerência}

Para Min et al. (2005), o alinhamento interno envolve a determinação do que precisa ser feito internamente à organização e o que precisa ser cumprido pelos parceiros externos e, para garantir este alinhamento, é necessário o envolvimento da alta gerência. É importante o suporte de pessoas com poder de decisão para que ocorram investimentos financeiros e não financeiros. Além disso, para o compartilhamento de informações e comunicação entre os agentes da cadeia de suprimentos, é necessária a interação entre as altas gerências com o objetivo de identificar oportunidades e áreas de melhorias (MIN et al., 2005).

A reunião executiva $S \& O P$ requer a participação de representantes da alta gerência para tomar decisões a respeito das recomendações discutidas nas fases anteriores e resolver conflitos (WALLACE, 2004). Lapide (2004) reforça a necessidade da participação de pessoas com poder de decisão no S\&OP. Segundo Lambert (2008), cada processo de negócio, sendo a gestão da demanda um dos processos, é liderado por uma equipe interfuncional na gestão da cadeia de suprimentos composta por gerentes de cada função de negócios, incluindo: Marketing, Vendas, Finanças, Produção, Compras, Logística e Pesquisa e Desenvolvimento.

Portanto, analisando a Figura 1, o processo de gestão da demanda envolve compreender o mercado por meio da análise das capacidades, restrições e oportunidades do ambiente externo. Este conhecimento do mercado, aliado às diretrizes e práticas estratégicas e operacionais da empresa objetivam desenhar um sistema operacional eficiente para sincronizar demanda e suprimentos por meio das previsões de vendas. Para a elaboração destas, a empresa precisa ter uma orientação para a cadeia de suprimentos que consiste no estabelecimento de esforços cooperativos entre funções internas e agentes externos à empresa com o objetivo de atender às necessidades do consumidor final e obter vantagem competitiva. Os planos de 
negócio são desenvolvidos com base na previsão de vendas feita por equipes interfuncionais das empresas da cadeia de suprimentos. Estas equipes também têm a responsabilidade pela execução e pelo acompanhamento do plano de negócios, buscando alternativas conjuntas para melhor atender o cliente e redirecionar ações em situações divergentes do planejado. Todo o processo de gestão da demanda deve ser suportado pela alta gerência da empresa para garantir a implantação do processo com sucesso.

O próximo tópico discute a metodologia utilizada para desenvolver esta pesquisa.

\section{Metodologia}

O método estudo de caso único foi adotado nesta pesquisa. Segundo Yin (2005, p. 32),

[...] um estudo de caso é uma investigação empírica que investiga um fenômeno contemporâneo dentro do contexto da vida real, especialmente quando os limites entre fenômeno e contexto não estão claramente definidos.

Esta seção foi dividida em três tópicos: a empresa focal, coleta de dados e análise dos dados. Cada um destes tópicos será discutido a seguir.

\subsection{A empresa focal}

O estudo de caso único realizado nesta pesquisa se justifica por ser um caso representativo e revelador, conforme será discutido nos próximos parágrafos.

Para atingir o objetivo proposto, a pesquisa empírica precisava envolver empresas pertencentes a uma cadeia de suprimentos que apresentassem as melhores práticas de gestão da demanda. A empresa Martins trabalha com 16.000 itens de produtos em diversos segmentos de negócio (farmácia, eletrônicos e informática, varejo alimentar, materiais de construção e veterinário), atua em todas as cidades do Brasil com 370.000 clientes, possui uma rede de supermercados independentes com quase 1.300 lojas, possui diversos centros de distribuição, mais de 6.000 vendedores, uma estrutura de televendas com 1.000 funcionários, é líder nacional como empresa atacadista distribuidora com faturamento em 2009 de R \$ 3,50 bilhões (RANKING..., 2010). Assim, conforme os dados mencionados, a empresa Martins apresenta uma complexidade de gestão da demanda, sendo líder de um setor que é responsável por 52,2\% do mercado de consumo do varejo mercearil (alimentos, bebidas, limpeza, higiene e beleza) segundo dados do Ranking ABAD/Nielsen (RANKING..., 2010).

Além disso, a empresa Martins desenvolve com os principais fornecedores o Joint Business Planning (JBP - Planejamento Conjunto do Negócio), estabelecendo um plano de negócios com o fornecedor para atingir metas estabelecidas em conjunto. A empresa também possui uma cultura interna de compartilhamento de informações com fornecedores. Desta forma, a cadeia de suprimentos, envolvendo a análise da díade Martins e seus principais fornecedores de produtos de mercearia básica, fornece um caso representativo por se tratar de empresas, em sua maioria, líderes no mercado em que atuam e, no caso específico das empresas fornecedoras, com marcas de produtos solidificadas no mercado.

As empresas fornecedoras que participaram desta pesquisa são consideradas pelo atacadista como Top Supplier Service (TSS). Os critérios da empresa para ser considerado um fornecedor TSS são relevância e rentabilidade do mix de produtos para o negócio do atacadista, faturamento total anual com o Martins e nível de relacionamento. Neste sentido, o nível de relacionamento está relacionado ao interesse do fornecedor em distribuir seus produtos por meio do canal atacadista, especificamente pela empresa Martins. Este interesse se reflete na capacidade do fornecedor de trabalho em conjunto com o atacadista, de planejamento e de investimento, como também na aproximação de equipes das duas empresas. O Martins possui alguns fornecedores com marcas líderes no mercado, mas que não têm interesse estratégico em desenvolver parcerias com o canal indireto.

A cadeia de suprimentos em análise também se caracteriza como um caso revelador, pois explora empiricamente a implantação da gestão da demanda entre os elos atacadista e seus principais fornecedores e não há trabalhos científicos publicados que descrevam e analisem a implantação da gestão da demanda na cadeia de suprimentos.

\subsection{Coleta de dados}

A condução do estudo de caso envolveu a coleta de informações por meio de relatórios e documentos fornecidos pelas empresas, pelo material público divulgado na imprensa, por observações diretas e entrevistas.

Para a realização das entrevistas, elaborou-se um roteiro composto de dezenove questões abertas com base na revisão da literatura realizada. $\mathrm{O}$ instrumento de coleta de dados foi dividido em quatro partes:

- Alinhamento interno das diretrizes estratégicas

Por meio das primeiras questões, buscava-se compreender como é o processo interno de alinhamento estratégico do fornecedor/atacadista distribuidor.

\section{- Planejamento das atividades de gestão da demanda}

A seguir, foram oito questões concernentes a como ocorre o planejamento das atividades de gestão da demanda entre o fornecedor e $\mathrm{o}$ atacadista distribuidor.

- Execução das atividades de gestão da demanda

Na sequência, cinco questões do roteiro indagaram a respeito de como o fornecedor e o atacadista 
distribuidor implantam e monitoram as atividades de gestão da demanda desenvolvidas em conjunto.

- Dificuldades, importância e incentivos da gestão da demanda

Finalmente, buscou-se obter a declaração da visão dos entrevistados sobre o que motiva as empresas a implantar a gestão da demanda na cadeia de suprimentos e quais dificuldades podem ser identificadas no processo por meio de três questões.

O Quadro 1 apresenta uma visão mais clara da associação entre as questões formuladas e os conceitos encontrados na literatura. Assim, verifica-se que, para cada objetivo, foram formuladas questões a partir dos tópicos concernentes aos requisitos para a gestão da demanda na cadeia de suprimentos discutidos na revisão da literatura. Além disso, foram inseridas, neste quadro, as referências utilizadas para cada um destes tópicos.

O Quadro 2 mostra as empresas e seus respectivos cargos entrevistados. O tempo de duração média das entrevistas foi de uma hora e meia. As áreas escolhidas para as entrevistas na empresa Martins foram Trade Marketing, Compras, Vendas e Logística por serem estas as mais envolvidas no processo de gestão da demanda. Nas entrevistas, foi solicitado aos executivos indicar fornecedores que melhor desenvolvessem a gestão da demanda com o atacadista, como também indicar empresas que estavam no estágio inicial de desenvolvimento da gestão da demanda com o atacadista ou que já desenvolvessem a gestão da demanda, mas que o Martins tinha mais dificuldade em conduzir o processo.

Foram realizadas entrevistas com representantes da área Comercial e/ou Trade Marketing de todas as empresas fornecedoras indicadas, pois eram estes que estavam diretamente envolvidos com o processo de gestão da demanda com o Martins.

Utilizou-se observação direta na visita ao centro de distribuição da empresa Martins na cidade de Uberlândia (MG) e na visita à área de Suprimentos desta mesma empresa na qual foi observado o funcionamento do sistema de informação de ressuprimento de estoques. Antes ou após as entrevistas realizadas na empresa Martins, as pesquisadoras eram convidadas a tomar um café na praça central dentro do prédio da empresa. Nestes momentos, tiveram oportunidade de observar o constante movimento dos fornecedores, o relacionamento e a interação deles com os funcionários do Martins.

\subsection{Análise dos dados}

Os dados obtidos foram submetidos à análise de conteúdo que, segundo Bauer (2002), consiste no estudo de transcrições textuais de dados visando comparar, observar diferenças e categorizar fatores presentes no texto por meio do processamento da informação.

De acordo com a recomendação de King (1998), após a leitura minuciosa das transcrições e da observação de códigos relevantes para o contexto da pesquisa, elaborou-se uma versão do template para a análise das entrevistas e, à medida que as entrevistas eram lidas, para efeito de codificação, observou-se a ocorrência de códigos que não se encaixavam nas categorias preestabelecidas, acrescentando, assim, outras categorias. As categorias preestabelecidas foram:

- Alinhamento interno das diretrizes estratégicas;

- Desenvolvimento do plano de negócios conjunto;

- Execução e acompanhamento do plano de negócios;

- Dificuldades do processo de gestão da demanda; e

- Importância e incentivos da gestão da demanda.

As transcrições das entrevistas realizadas na pesquisa de campo foram incluídas individualmente no programa NVivo9, como fontes documentais. Este programa é um aplicativo que possibilita a codificação de textos e gerenciamento das informações para apoio à análise dos dados. Suas funções permitem a divisão do texto em segmentos, a codificação desses segmentos e a explicitação de todas as instâncias codificadas. À medida que a leitura atenta e cuidadosa de cada entrevista era efetuada, as ideias, conceitos ou aspectos relevantes para o tema da pesquisa foram sendo destacados e referenciados como códigos, com o apoio do programa utilizado.

Convém destacar que, ao se identificar um código no texto em análise, o programa NVivo9 possibilita que ele seja selecionado e associado a uma determinada categoria ou subcategoria, cadastrada a critério do usuário. A separação por temas, classificados sob a forma de categorias e subcategorias, associada à combinação de perspectivas dos diversos entrevistados, contribuiu para a interpretação dos dados.

A análise das 18 entrevistas possibilitou a codificação de 746 referências passíveis de classificação nas categorias e subcategorias apresentadas no Quadro 3, bem como o número de entrevistas que representaram fontes de dados para a codificação e o número de referências obtidas.

Mensagens por e-mail foram trocadas com alguns entrevistados, como também chamadas telefônicas foram realizadas para esclarecer algumas questões que não ficaram claras durante a análise dos dados. Ao finalizar todas as análises, os resultados obtidos foram discutidos e validados separadamente com quatro representantes da empresa Martins, um da Colgate-Palmolive e um da Johnson \& Johnson. A duração de cada discussão foi cerca de 1 hora e 15 minutos, todas foram gravadas, pontos importantes transcritos e foram envolvidos três executivos e uma empresa fornecedora que não haviam participado 







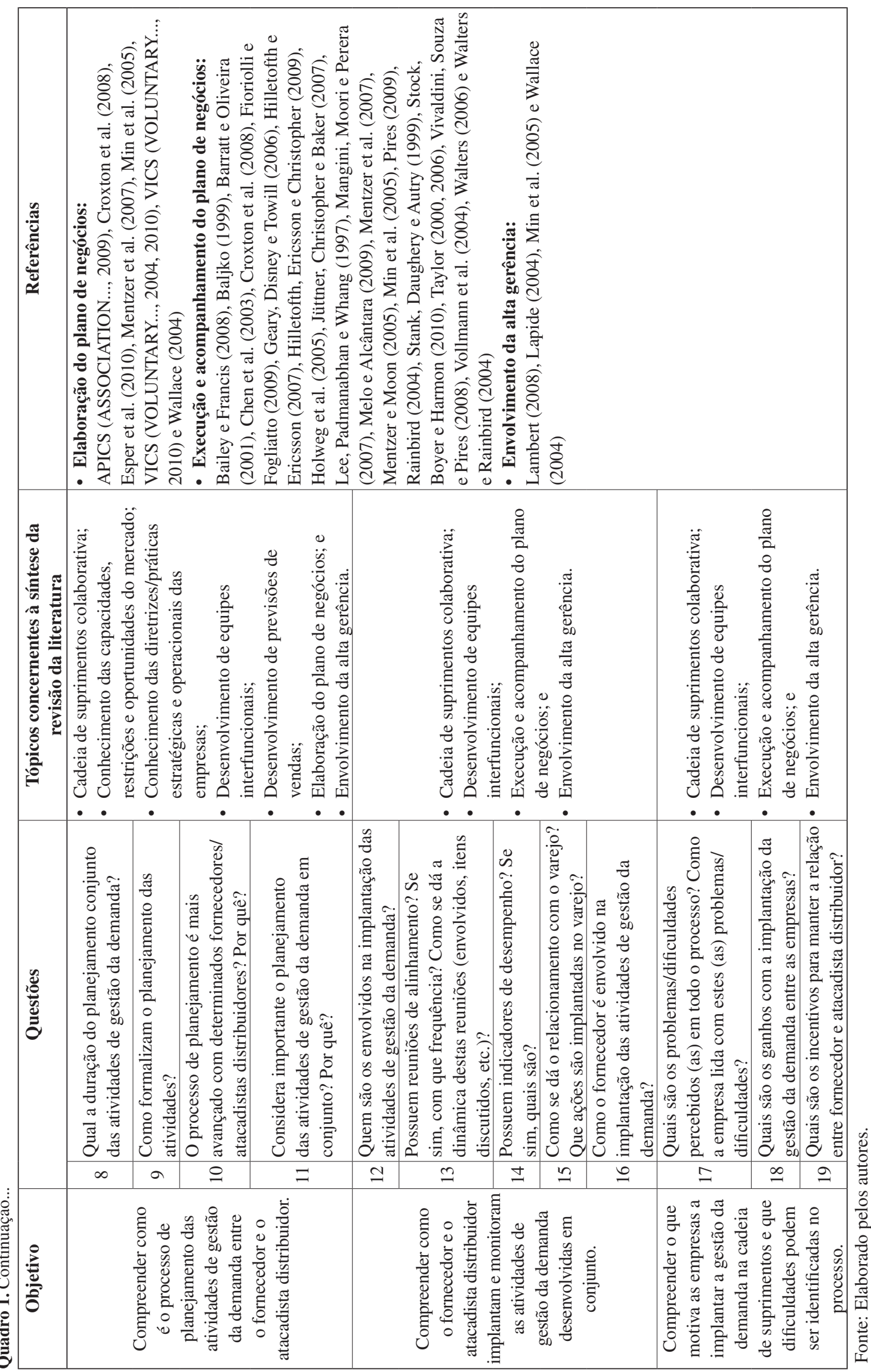


Quadro 2. Empresas e seus respectivos representantes entrevistados.

\begin{tabular}{|l|l|c|}
\hline \multicolumn{1}{|c|}{ Empresas } & \multicolumn{1}{|c|}{ Cargo dos entrevistados } & Entrevistas \\
\hline \multirow{4}{*}{ Martins (empresa focal) } & Gerente de Compras (produtos de higiene, beleza e limpeza) & 1 \\
\cline { 2 - 3 } & Gerente de Compras (produtos alimentícios) & 1 \\
\cline { 2 - 3 } & Gerente de Vendas & 1 \\
\cline { 2 - 3 } & Gerente de Trade Marketing & 1 \\
\cline { 2 - 3 } & Gerente de Planejamento Logístico & 1 \\
\cline { 2 - 3 } & Gerente de Suprimentos & 1 \\
\hline \multirow{2}{*}{ Bombril } & Supervisor de Vendas & 1 \\
\hline \multirow{2}{*}{ Colgate-Palmolive } & Gerente de Vendas & 1 \\
\cline { 2 - 3 } & Diretor de Planejamento da Demanda & 1 \\
\hline Diageo & Gerente de Trade Marketing & 1 \\
\hline \multirow{2}{*}{ Garoto } & Gerente de Trade Marketing & 1 \\
\cline { 2 - 3 } & Vendedor & 1 \\
\hline Kraft & Gerente de Vendas & 1 \\
\hline \multirow{2}{*}{ L'Oréal Brasil } & Diretor de Trade Marketing \& Merchandising & 1 \\
\cline { 2 - 3 } & Gerente Key Account & 18 \\
\hline Procter \& Gamble & Gerente de Vendas & 1 \\
\hline Unilever & Gerente de Vendas & 1 \\
\hline Total de entrevistas & & \\
\hline
\end{tabular}

inicialmente na fase de coleta de dados, indicados pelos representantes da empresa Martins.

A discussão e a validação dos resultados com os executivos das empresas possibilitaram esclarecer alguns pontos e dúvidas que ainda estavam pendentes e aprofundar alguns itens. A participação de executivos e de uma outra empresa fornecedora que não foram envolvidos na fase de coleta de dados foi importante porque surgiram novas contribuições e deu mais validade e confiabilidade aos resultados obtidos. Importante ressaltar que, em nenhum momento, os executivos discordaram dos resultados obtidos, pelo contrário, forneceram mais detalhes, enriquecendo a pesquisa. Portanto, ao todo, foram pesquisadas nove empresas fornecedoras do Martins.

O próximo tópico apresenta os resultados da pesquisa.

\section{Resultados}

Depois da análise dos dados coletados foi possível mapear como a gestão da demanda pode ser implantada na prática. Assim, a Figura 2 mostra o modelo de gestão da demanda proposto a partir dos casos estudados por meio das experiências de executivos de grandes empresas, como também a partir da revisão da literatura que contribuiu para a estruturação do modelo.

O processo de gestão da demanda é dividido em três etapas: 1) alinhamento conjunto das diretrizes estratégicas das empresas; 2) formulação do plano de negócios; e 3) execução e acompanhamento do plano de negócios. Além disso, apresenta três elementos que permeiam todo o processo: envolvimento da alta gerência, interações inter e intraempresas e os resultados da gestão da demanda. As etapas e os resultados da gestão da demanda serão discutidos a seguir.

\subsection{Etapa 1: Alinhamento conjunto das diretrizes estratégicas das empresas}

O Quadro 4 resume as atividades desenvolvidas nesta etapa. Atacadista distribuidor e fornecedor compartilham informações e discutem as previsões de vendas realizadas por cada empresa. É importante que as empresas tenham um sistema de informação capaz de gerar dados detalhados como vendas por região, categoria, subcategoria e segmentos de negócios. Além disso, as empresas devem criar equipes interfuncionais compostas por representantes das áreas de Marketing, Compras, Vendas e Operações (Produção e ou Logística), pois estas equipes serão responsáveis pelo alinhamento inter e intraempresas.

Diversos autores (CHEN; DAUGHERTY; ROATH, 2009; CROXTON et al., 2008; HILLETOFTH; ERICSSON; CHRISTOPHER, 2009; JÜTTNER; CHRISTOPHER; BAKER, 2007; MENTZER et al., 2007; VOLLMANN et al., 2004) defendem que o processo de gestão da demanda deve envolver uma equipe interfuncional composta por integrantes de diversos níveis e setores da organização, bem como representantes estratégicos da cadeia de suprimentos (fornecedores e clientes). Esta equipe interfuncional 
deve ter uma ampla compreensão do mercado, das diretrizes e práticas estratégicas e operacionais da organização (CROXTON et al., 2008; ESPER et al., 2010; HILLETOFTH; ERICSSON; CHRISTOPHER, 2009; MENTZER et al., 2007).
As relações próximas são desenvolvidas primeiramente entre áreas funcionais dentro de uma organização e esta interdependência funcional interna estabelece uma base para uma parceria externa, resultando na integração de atividades

Quadro 3. Categoria e subcategorias de análise.

\begin{tabular}{|c|c|c|c|}
\hline Categoria & Subcategoria & Fontes & Referências \\
\hline \multirow{3}{*}{$\begin{array}{l}\text { Alinhamento interno das diretrizes } \\
\text { estratégicas }\end{array}$} & Alinhamento interno fornecedor & 10 & 40 \\
\hline & Alinhamento interno Martins & 5 & 6 \\
\hline & Fontes de dados e previsões de vendas & 15 & 20 \\
\hline $\begin{array}{c}\text { Colgate-Palmolive como referência } \\
\text { de melhor prática }\end{array}$ & - & 6 & 14 \\
\hline Compartilhamento de informações & - & 15 & 20 \\
\hline Concorrentes Martins & - & 8 & 10 \\
\hline \multirow{6}{*}{$\begin{array}{l}\text { Desenvolvimento do plano de } \\
\text { negócios conjunto }\end{array}$} & Ações e formato do plano de negócios & 10 & 34 \\
\hline & Alinhamento atacadista distribuidor e fornecedor & 14 & 55 \\
\hline & Duração e horizonte de planejamento & 9 & 12 \\
\hline & Fechamento do plano de negócios & 12 & 37 \\
\hline & Nível de detalhes & 5 & 10 \\
\hline & Reunião Top to Top & 11 & 21 \\
\hline Diferencial Martins & - & 12 & 33 \\
\hline \multirow{5}{*}{$\begin{array}{l}\text { Dificuldades do processo de gestão } \\
\text { da demanda }\end{array}$} & $\begin{array}{l}\text { Compras concentradas na última semana do mês } \\
\text { e de oportunidade }\end{array}$ & 13 & 29 \\
\hline & $\begin{array}{l}\text { Dificuldades de comunicação com a equipe de } \\
\text { vendas e desenvolvimento do ponto de venda }\end{array}$ & 12 & 20 \\
\hline & $\begin{array}{l}\text { Dificuldade dos fornecedores de cumprir a } \\
\text { programação de entrega de mercadorias na } \\
\text { empresa Martins }\end{array}$ & 7 & 8 \\
\hline & Falta cultura de planejamento conjunto & 5 & 16 \\
\hline & $\begin{array}{c}\text { Gerenciar uma grande quantidade de iniciativas } \\
\text { e categorias }\end{array}$ & 4 & 6 \\
\hline \multirow{4}{*}{$\begin{array}{l}\text { Equipes, áreas, cargos envolvidos } \\
\text { no processo de gestão da demanda }\end{array}$} & Áreas envolvidas na gestão da demanda & 16 & 44 \\
\hline & Envolvimento da alta gerência & 13 & 23 \\
\hline & Equipe interfuncional & 11 & 26 \\
\hline & Key account fornecedor & 6 & 7 \\
\hline \multirow{3}{*}{$\begin{array}{l}\text { Execução e acompanhamento do } \\
\text { plano de negócios }\end{array}$} & Execução do plano de negócios & 16 & 72 \\
\hline & Indicadores de desempenho & 18 & 56 \\
\hline & Reuniões de revisão do plano & 12 & 20 \\
\hline \multirow{2}{*}{ Força de vendas Martins } & Diferenças vendedor RCA e CLT & 3 & 5 \\
\hline & Vendedores próprios CLTs & 5 & 10 \\
\hline $\begin{array}{l}\text { Importância e incentivos da gestão } \\
\text { da demanda }\end{array}$ & - & 18 & 32 \\
\hline Lojas Smart & - & 1 & 1 \\
\hline $\begin{array}{l}\text { Periodicidade de compras do } \\
\text { Martins }\end{array}$ & - & 7 & 12 \\
\hline Segmentação de clientes & - & 3 & 11 \\
\hline Segmentação de fornecedores & - & 3 & 6 \\
\hline Sistema de informação fornecedor & - & 11 & 18 \\
\hline Sistema de informação Martins & - & 7 & 12 \\
\hline \multicolumn{3}{|l|}{ Total de códigos: } & 746 \\
\hline
\end{tabular}

A coluna 'Fontes' refere-se ao número de entrevistas que representaram fontes de dados para a codificação e a coluna 'Referências' é o número de códigos adicionados à categoria ou subcategoria. Fonte: Análise dos dados. 


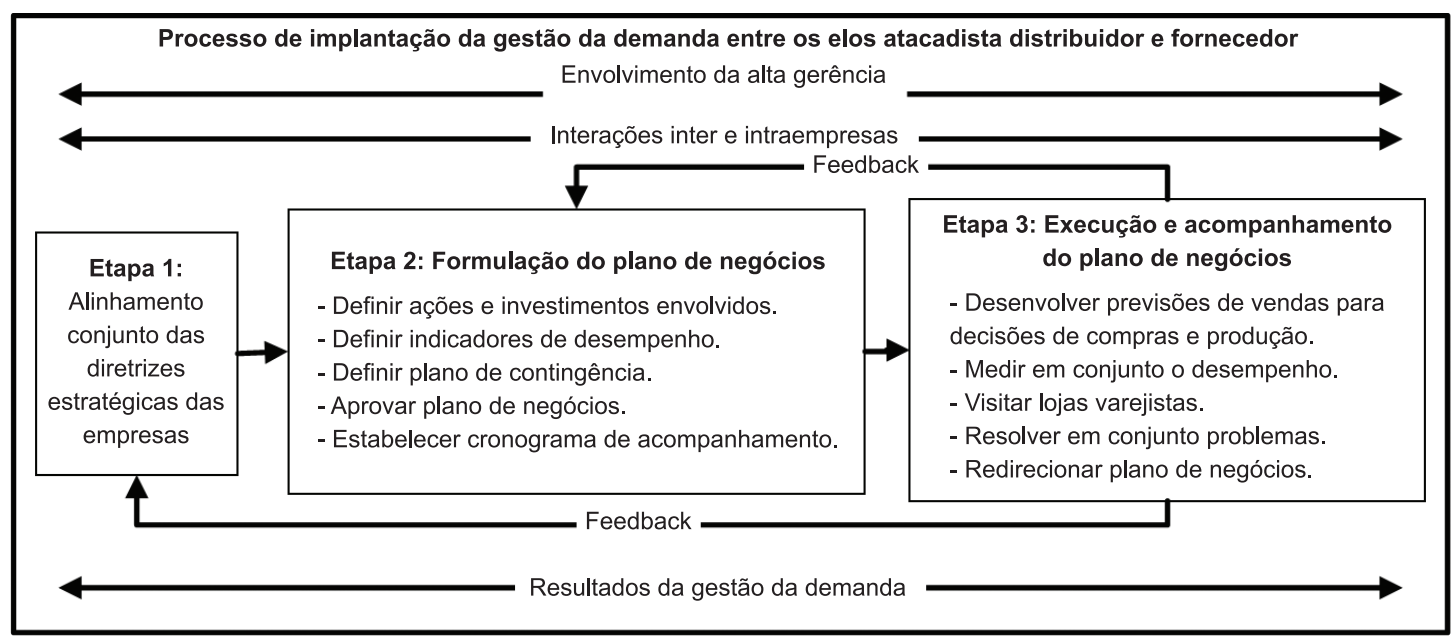

Figura 2. Modelo de gestão da demanda na cadeia de suprimentos de produtos de mercearia básica envolvendo os elos atacadista distribuidor e fornecedor. Fonte: Resultados da análise dos dados.

Quadro 4. Etapa de alinhamento conjunto das diretrizes estratégicas das empresas.

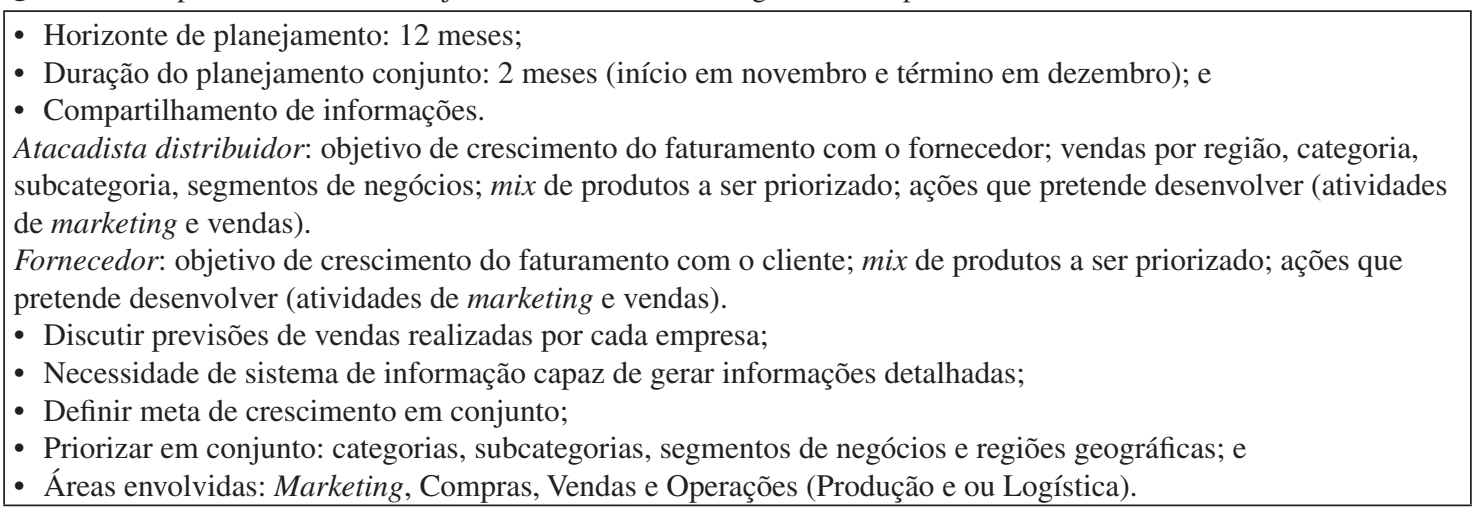

Fonte: Resultados da análise dos dados.

intra e interfirmas (FLYNN; HUO; ZHAO, 2010; GIMENEZ, 2006; LAMBERT, 2008; MIN et al., 2005; VAN HOEK; MITCHELL, 2006).

Recomenda-se que o alinhamento conjunto se inicie quando as empresas tiverem definido suas diretrizes estratégicas, porém as discussões devem começar e finalizar até o início do ano que está sendo planejado para não comprometer as ações e os investimentos. $\mathrm{O}$ resultado destas discussões é a priorização de categorias, subcategorias, segmentos de negócios e regiões geográficas para que as empresas possam direcionar seus esforços de vendas e marketing.

A alta gerência deve ser envolvida nesta etapa para garantir o alinhamento interno e o que precisa ser cumprido pelos parceiros externos, conforme defendem Min et al. (2005). Segundo estes autores, é importante o suporte de pessoas com poder de decisão para que ocorram investimentos financeiros e não financeiros. Além disso, para o compartilhamento de informações e comunicação entre os agentes da cadeia de suprimentos, é necessária a interação entre as altas gerências com objetivo de identificar oportunidades de melhorias.

\subsection{Etapa 2: Formulação do plano de negócios}

Nesta etapa, são desenvolvidas as seguintes atividades:

- Definir ações e investimentos envolvidos;

- Definir indicadores de desempenho;

- Definir plano de contingência;

- Aprovar plano de negócios; e

- Estabelecer cronograma de acompanhamento.

O Quadro 5 representa as principais discussões realizadas em cada uma destas atividades, como também são propostos alguns questionamentos que podem auxiliar na identificação das ações do plano de negócios.

Desta forma, após o alinhamento conjunto das diretrizes estratégicas das empresas, as equipes interfuncionais formularão o plano de negócios que 
Quadro 5. Etapa de formulação do plano de negócios.

\section{Etapa 2: Formulação do plano de negócios}

\section{Definir ações e investimentos envolvidos:}

Questões que podem auxiliar a identificar as ações:

Ações gerais:

- Direcionar para qual segmento de negócios?

- Qual estratégia para cada categoria?

- Qual o sortimento, a região ou o segmento de negócios deve ter com a categoria/marca?

Qual mix de produtos será trabalhado?

Ações que envolvam o atacadista distribuidor:

- Quais são as metas por categoria e região?

- Quais são as iniciativas para desenvolver/capacitar sua equipe de vendas?

- Quais iniciativas para expansão da equipe de vendas?

- Qual o plano de comunicação para a equipe de vendas?

- Quais são os incentivos de vendas aos vendedores? Comissões diferenciadas? Premiações? Quando ocorrerá?

- Quais são as campanhas de vendas que darão foco?

- Como será a abordagem em relação à segmentação dos clientes?

- Quais são as iniciativas para desenvolver o varejista?

- Como será a distribuição (quantidade de lojas atendidas) por categoria e região?

Ações que envolvam o fornecedor:

- Que ações de mídia irá desenvolver? Quais canais de comunicação? Em quais regiões?Em que períodos durante o ano?

- Quais são os lançamentos de produtos? Quando?

- Irá desenvolver packs promocionais? Quando?

- Quais eventos para a força de vendas irão participar?

- Em quais campanhas promocionais investirá?

- Como divulgar os produtos para a força de vendas do atacadista distribuidor?

- Quanto de investimento com tabloides/encartes (jornal de comunicação das ofertas da loja varejista)? Disponibilizarão material de visibilidade no ponto de venda (ex: displays)?

- Como será a política de preço?

\section{Definir indicadores de desempenho:}

- Faturamento de vendas para o varejista, faturamento de compras do fornecedor, margem bruta, margem de contribuição;

- Valor em estoque, prazo médio de estoque, ruptura, capital de giro, tempo médio de entrega da mercadoria pelo fornecedor em relação ao prazo acordado e volume entregue em relação ao volume solicitado;

- Desempenho de vendas por categoria, centro de distribuição, segmento de negócios, canal de vendas, regiões Nielsen;

- Número de lojas varejistas com vendas efetivadas; e

- Quantidade de itens por pedido.

\section{Definir plano de contingência:}

- Definir ações para falhas de fornecimento.

- Definir ações para rupturas no ponto de vendas e no atacadista distribuidor.

\section{Aprovar plano de negócios:}

- Participação de executivos com poder de decisão.

- Resolver conflitos.

Estabelecer cronograma de acompanhamento:

- Estabelecer periodicidade de relatórios a serem disponibilizados aos fornecedores;

- Estabelecer reuniões periódicas para acompanhamento do plano; e

- Mensais envolvendo gerências, trimestrais envolvendo diretorias e semestrais envolvendo presidências e ou vice-presidências.

Fonte: Resultados da análise dos dados.

consiste num conjunto de ações e investimentos a serem desenvolvidos ao longo do horizonte de planejamento de 12 meses com o objetivo de atingir as metas de crescimento definidas na etapa anterior. O plano de negócios deve conter as ações que cada empresa desenvolverá individualmente e em conjunto, como também os investimentos envolvidos em cada iniciativa e o período em que ocorrerão.

As equipes interfuncionais precisam desenvolver uma estrutura de indicadores para medir e monitorar o processo de gestão da demanda (CROXTON et al., 2008). Assim, são propostos no Quadro 5 alguns indicadores de desempenho para que o atacadista distribuidor e fornecedores possam acompanhar os resultados do plano de negócios estabelecido.

Recomenda-se que as empresas desenvolvam um plano de contingência para estabelecer ações alternativas em casos de falhas de fornecimento e rupturas no ponto de vendas e no atacadista distribuidor, permitindo melhor gestão de riscos. Segundo Croxton et al. (2008), a formulação de planos de contingência é fundamental para gerenciar a consequência de eventos que podem comprometer a capacidade da empresa em atender à demanda.

O plano de negócios deve ser aprovado pela alta gerência para gerar comprometimento das equipes interfuncionais que serão as responsáveis por garantir a execução do plano. Esta aprovação pode ocorrer numa reunião em que estarão presentes executivos com poder de decisão das duas empresas. Wallace (2004) ressalta que os conflitos devem ser resolvidos na reunião executiva e as decisões devem ser tomadas pela alta gerência. 
As equipes interfuncionais precisam definir a periodicidade que os relatórios dos indicadores de desempenho serão disponibilizados aos fornecedores, como também o cronograma de reuniões e quem serão os envolvidos nestas reuniões. A interação entre as equipes interfuncionais deve ser diária e as empresas podem estabelecer reuniões mensais com gerências, trimestrais envolvendo diretorias e semestrais com presidências e ou vice-presidências para garantir maior envolvimento da alta gerência no processo de gestão da demanda. Um representante do fornecedor relata:

Temos revisões mensais, trimestrais e semestrais nas quais fazemos uma grande revisão. Nas reuniões trimestrais ou semestrais, vêm a presidência, a diretoria, a vice-presidência das empresas. Daí discutimos: nós falamos que vamos fazer isto, temos estes resultados até este momento. Como nós estamos? Estamos ok, não $o k$, estamos atrasados, o que está faltando fazer. Nestas reuniões, estão presentes pessoas que têm poder de decisão e são muito produtivas por causa disto. 'Se estou com problema, o que está travado? Estou travado por causa disto. Por quê? Ah, então pode mandar fazer...'. Então acaba destravando isto.

Lapide (2004) defende que essas reuniões devem ser periódicas, com agenda estruturada, que tenham participação interfuncional e representantes com poder de decisão, como também que os participantes tenham preparação anterior às reuniões.

\subsection{Etapa 3: Execução e acompanhamento do plano de negócios}

Nesta etapa, as empresas devem executar as ações desenvolvidas e formalizadas no plano de negócios. Os indicadores de desempenho desenvolvidos na etapa anterior serão utilizados para monitorar se o que foi planejado está sendo realizado. O Quadro 6 apresenta questões que podem auxiliar as discussões nesta etapa.

As empresas podem utilizar técnicas quantitativas de previsões de vendas para apoiar as decisões de quais itens comprar do fornecedor, no caso do atacadista distribuidor, e quais itens produzir, no caso do fornecedor. Autores como Mentzer et al. (2007) defendem que o emprego de cada técnica de previsão de vendas está condicionado às circunstâncias em que são aplicadas.

Tanto o atacadista distribuidor, quanto os fornecedores, devem visitar as lojas varejistas com frequência. Nestas visitas, é indispensável que os representantes das empresas:

- Verifiquem o planograma recomendado: se os produtos estão expostos de maneira correta nas gôndolas, espaço disponível para os produtos na gôndola, se tem display, se tem ponto extra, se os produtos que estão recebendo investimento em mídia estão disponíveis no ponto de venda, sortimento mínimo para cada formato de loja;

- Analisem o comportamento de preço (barato, caro, aceitável) e os produtos dos concorrentes;

- Conversem com o proprietário ou o gerente da loja para verificar a frequência de visitas da força de vendas, se tem conhecimento das campanhas de marketing ou promoções ativas; e

- Identifiquem as razões pelos quais as vendas de determinados produtos estão com desempenho baixo ou os motivos pelos quais a loja não compra determinados produtos do atacadista distribuidor.

Estas visitas permitem melhorar a comunicação com os vendedores, proporcionar-lhes treinamento, monitorar a implementação das ações desenvolvidas nas lojas varejistas, além de identificar oportunidades de melhorias no processo de gestão da demanda.

Quadro 6. Questões que podem auxiliar as discussões na etapa de execução e acompanhamento do plano de negócios.

Perguntas que podem auxiliar a discussão:

- O plano foi bem desenvolvido? Onde ocorreu o erro?

- Atacadista distribuidor está praticando uma margem muito alta, dificultando a venda?

- O problema está no preço? Na entrega?

- Alta rotatividade de vendedores do atacadista distribuidor?

- Falta de capacitação dos vendedores? Problema de comunicação com a força de vendas?

- Os investimentos do fornecedor foram suficientes?

- A campanha de vendas desenvolvida pelo atacadista distribuidor foi adequada para aquela (e) região, categoria, subcategoria, segmento de negócio?

- O alcance da mídia desenvolvida pelo fornecedor foi suficiente para gerar demanda?

- Problema de fornecimento de matéria-prima para produção de determinados produtos? Outras linhas precisam ser priorizadas para redirecionar as metas?

- Reação dos concorrentes? Precisa de mais investimentos?

Fonte: Resultados da análise dos dados. 
Por fim, as interações inter e intraempresas favorecem a resolução conjunta de problemas e o redirecionamento do plano quando necessário. $\mathrm{O}$ envolvimento da alta gerência nesta etapa agiliza as decisões de redirecionamento do plano, como também garante que as ações sejam cumpridas pelas equipes interfuncionais.

\subsection{Resultados da gestão da demanda}

Foram identificados como resultados da gestão da demanda entre as empresas pesquisadas maior eficiência e eficácia no atendimento da demanda, que conduzem a maior rentabilidade para as empresas. Conforme Min et al. (2005), a eficiência está relacionada à utilização dos recursos de forma adequada e a eficácia se refere ao grau de cumprimento das metas estabelecidas.

Assim, as empresas pesquisadas conseguem maior eficiência com o melhor controle de estoques, compartilhamento de custos e melhor planejamento e controle da produção, e maior eficácia com o aumento das vendas e a melhoria do nível de serviço. Além destes benefícios, verifica-se o compartilhamento de conhecimento e aprendizado constante entre as empresas. Os próximos itens discutem cada um destes benefícios.

\subsubsection{Eficiência}

- Melhor controle dos estoques e desenvolvimento de ações conjuntas quando o nível de inventário estiver elevado

A empresa Martins compartilha um relatório mensal de indicadores de desempenho com os fornecedores e informações detalhadas sempre que estes solicitam. Percebe-se que os fornecedores que melhor desenvolvem a gestão da demanda com o atacadista distribuidor estão constantemente presentes nas instalações da empresa, solicitam informações diárias dos negócios, interagem com as equipes do Martins e apresentam soluções para redirecionamento do plano de negócios quando os resultados podem não ser alcançados. Essa postura proativa e ágil evita gerar níveis altos ou baixos de inventário.

Os entrevistados do Martins acreditam que esta abertura das informações facilita a comunicação e gera maior interação da empresa fornecedora no andamento dos negócios. Um representante do Martins comenta:

O Martins é uma plataforma de negócios, zona franca. Eu tenho obrigação de prestar conta para estes caras (fornecedores) constantemente. Eu emito relatórios todas as vezes que a gente se encontra. Como eles são muitos, a gente não tem uma agenda, mas para cada uma das atividades previstas no plano, a gente tem um acompanhamento conjunto, gera os relatórios, os caras sentam na nossa mesa, abrem o notebook deles, conectam a internet wireless (damos acesso a eles) e trabalhamos aqui dentro. Os meus analistas trabalham com estes caras o dia inteirinho.

É unânime entre todos os entrevistados a abertura do Martins em relação ao compartilhamento de informações. Diversos autores ressaltam a necessidade de um fluxo de informação transparente na gestão da cadeia de suprimentos para reduzir as distorções da demanda (BALJKO, 1999; LEE; PADMANABHAN; WHANG, 1997; PAIK; BAGCHI, 2007).

Porém, somente o compartilhamento de informações não garante o melhor controle dos estoques, é necessário o envolvimento inter e intraempresas (ASSOCIATION..., 2009; CROXTON et al., 2008; ESPER et al., 2010; HILLETOFTH; ERICSSON; CHRISTOPHER, 2009; JÜTTNER; CHRISTOPHER; BAKER, 2007; MENTZER et al., 2001; MEUNIERFITZHUGH; PIERCY, 2007; VOLUNTARY..., 2010; VAN HOEK; MITCHELL, 2006; VOLLMANN et al., 2004). Assim, além do compartilhamento de informações, as empresas que interagem com as equipes interfuncionais do Martins conseguem controlar melhor os estoques e desenvolver soluções em conjunto para diminuir o inventário quando estiver elevado.

- Compartilhamento dos custos e esforços para desenvolver as iniciativas, campanhas de vendas e ações promocionais para o varejista e para a força de vendas

O desenvolvimento do plano de negócios gera compromisso das empresas em investir recursos financeiros nas iniciativas, campanhas de vendas e ações promocionais desenvolvidas para o varejista e para a força de vendas. Esse plano fornece às empresas uma previsão da abrangência e da profundidade das ações a serem desenvolvidas, como também estabelece o período em que estas ocorrerão, permitindo prepará-las com antecedência e garantir orçamento para que ocorram.

Alguns entrevistados das empresas fornecedoras citaram que a gestão da demanda com o Martins é importante para o desenho das campanhas de lançamento de novos produtos do fornecedor. A equipe de Vendas e Trade Marketing do fornecedor juntamente com a equipe de Trade Marketing e Compras do Martins desenham as iniciativas para lançamento do produto: regiões a priorizar, em quais segmentos de negócio e formatos de lojas vender, metas de vendas, formação de preço, investimento, campanhas de vendas e promoções.

- Melhor planejamento e controle da produção dos fornecedores

Os entrevistados das empresas fornecedoras consideram importante o desenvolvimento do plano de negócios conjunto porque conseguem melhor 
planejamento e controle da produção, têm uma previsão mais acurada de quanta matéria-prima será necessária para atender à demanda dos produtos. Além disso, o plano de negócios gera uma segurança para o atacadista distribuidor quanto à capacidade produtiva e de abastecimento do fornecedor.

\subsubsection{Eficácia}

\section{- Aumento das vendas}

O aumento das vendas é consequência de várias melhorias, entre elas maior disponibilidade dos produtos, melhoria da comunicação com a força de vendas e maior capacitação desta.

Maior disponibilidade dos produtos: todos os entrevistados das empresas fornecedoras mencionaram que têm como diretriz estratégica aumentar o número de lojas varejistas que possuem os produtos da empresa e garantir que estas lojas tenham o sortimento e exposição dos produtos adequados. Neste sentido, quando o Martins apresenta sua proposta de trabalho para atingir estes objetivos e realmente transforma, em conjunto com o fornecedor, o planejamento em resultados para as empresas, o atacadista distribuidor é percebido como a melhor opção de distribuição dos produtos dos fornecedores. Um representante da empresa fornecedora relata os resultados percebidos com a gestão da demanda:

A gente observa que quem se alia ao Martins, $e$ tem um trabalho de planejamento comum, os níveis de crescimento de vendas são muito maiores do que aquelas indústrias que não se planejam e não têm nenhum vínculo estratégico com o Martins.

Melhoria da comunicação com a força de vendas por meio dos canais de comunicação (revistas, portal online da força de vendas, envio de ofertas por meio de correio eletrônico), contratação de vendedores, participações em eventos, simplificação da proposta comercial.

Maior capacitação da força de vendas: investimentos em treinamentos que reforcem as atividades de gestão da loja varejista como, por exemplo, identificar a necessidade de expositores de produtos, organizar as gôndolas e o planograma da loja, gerenciar estoques, o preço de venda ao consumidor e a margem de lucro do cliente, como também identificar oportunidades de aumentar o número de itens que a loja compra do Martins.

\section{- Melhoria do nível de serviço}

A gestão da demanda entre o Martins e fornecedores permite melhor visibilidade das diretrizes estratégicas de cada empresa, das tendências para o próximo ano, das previsões de vendas, a identificação de quais atividades norteiam o crescimento e o que as empresas precisarão investir para garantir este crescimento. Isto possibilita às empresas oferecer melhor nível de serviço às lojas varejistas, atendendo-as conforme suas necessidades e evitando rupturas no ponto de vendas. Além disso, a gestão da demanda permite aos parceiros melhor controle de estoque, evitando rupturas no atacadista distribuidor.

No alinhamento interno das diretrizes estratégicas, as empresas realizam análises das categorias e subcategorias por regiões e segmentos de negócios para identificar tendências de mercado, potencial de consumo, as oportunidades para alavancar as categorias. Este conhecimento é compartilhado e, em conjunto, desenvolvem um plano de negócios para atingir a meta de crescimento acordada. As empresas monitoram este plano, isto permite identificar ineficiências nos processos e solucioná-las em conjunto. Neste sentido, um dos representantes da empresa fornecedora menciona:

Monitoro com o cliente os resultados, porque você tem que levar isto para o seu cliente. As reuniões criam laços, são muito produtivas. Eliminam deficiências, melhoram processos dentro do cliente. Foi criada uma dinâmica muito grande de monitoramento do negócio que o cliente começou a cobrar 'olha, precisamos fazer isto'.

A eliminação de deficiências e melhoria de processos que o entrevistado menciona estão relacionadas ao melhor controle de estoque do atacadista distribuidor, maior eficiência Logística para garantir o abastecimento das lojas varejistas, interação entre as equipes interfuncionais das duas empresas para solucionar os problemas que surgem, evitando, assim, rupturas no ponto de venda ou no atacadista distribuidor. Segundo Syntetos et al. (2010), um controle efetivo dos estoques representa uma oportunidade para atingir um nível de serviço elevado, buscando equilibrar os custos.

No trecho citado, o entrevistado utilizou os termos "monitoro com o cliente" e "precisamos fazer isto", mostrando que os esforços para melhorar os resultados das empresas não são individuais. Isto também pode ser percebido no relato de um representante da empresa Martins que demonstra abertura ao fornecedor para sugestões de melhorias:

É o que a gente tem cobrado de muitos fornecedores: qual é a sua recomendação? $O$ que tem que fazer de diferente? O que vamos fazer para mudar? Ah, tem esta ação no Nordeste, tem que acertar o pricing nestas regiões [...]. Temos a informação, então façamos uma boa gestão.

\subsubsection{Compartilhamento de conhecimento e aprendizado constante}

Além da capacidade de distribuir os produtos do fornecedor em todo o território nacional, compartilhar informações detalhadas de toda a operação desenvolvida com o fornecedor, permitir o livre acesso dos 
fornecedores às instalações da empresa, o Martins tem conhecimento da gestão do pequeno e médio varejista. A empresa se especializou na prestação de serviços de distribuição a este segmento de negócio, possui uma rede de supermercados independentes, tem a Universidade Martins do Varejo que desenvolve projetos de lojas e treinamentos, como também possui uma força de vendas representativa. Além disso, duas empresas do grupo Martins fornecem serviços financeiros às lojas varejistas. Segundo os entrevistados das empresas fornecedoras, estas têm pouco conhecimento do comportamento do pequeno e médio varejista e de como se relacionar com estes clientes.

Os fornecedores, por sua vez, além de abastecer o atacadista distribuidor com seus produtos, que muitas vezes são líderes de mercado, e fornecer investimentos financeiros e não financeiros para o desenvolvimento do plano de negócios, podem oferecer ao Martins um conhecimento aprofundado da categoria de seus produtos. $\mathrm{O}$ atacadista distribuidor trabalha com muitos itens e sem o relacionamento mais próximo com o fornecedor fica difícil acompanhar as tendências de consumo de todos os produtos e ter acesso às pesquisas desenvolvidas pelos fornecedores. Um entrevistado da empresa Martins menciona:

Como ambas as partes estão tentando entrar em um acordo para um crescimento econômico, a gente lida com as diferenças com um nível de tolerância inimaginável. Eu preciso dela para vender e ela precisa de mim para vender. Há uma tentativa constante de alinhar os interesses. Há uma tentativa deles no sentido de nos ajudar a melhorar, e nós ajudarmos eles a melhorarem.

Assim, verifica-se que as empresas analisadas exercem o poder de especialização, conforme discutido por French Junior e Raven (1959), em que os dois elos podem oferecer conhecimento para a melhoria da gestão da demanda na cadeia de suprimentos.

\section{Conclusões}

Esta pesquisa teve como objetivo desenvolver um modelo para a gestão da demanda na cadeia de suprimentos de produtos de mercearia básica envolvendo os elos atacadista distribuidor e fornecedor. O processo de implantação pode ser dividido em três fases: 1) alinhamento conjunto das diretrizes estratégicas das empresas; 2) formulação do plano de negócios; e 3) execução e acompanhamento do plano de negócios. O envolvimento da alta gerência, interações inter e intraempresas e os resultados da gestão da demanda permeiam todo o processo.

A contribuição desta pesquisa está relacionada ao modelo de gestão da demanda representado pela Figura 2. Este modelo apresenta considerável implicação gerencial por fornecer um guia de como implantar a gestão da demanda na cadeia de suprimentos de produtos de mercearia básica. Autores, como Croxton et al. (2008), Esper et al. (2010), Hilletofth, Ericsson e Christopher (2009), Jüttner, Christopher e Baker (2007), Mentzer e Moon (2005) e VICS (VOLUNTARY..., 2010), propuseram abordagens para a gestão da demanda na cadeia de suprimentos destacando suas interações e sua importância, mas não exploraram empiricamente como as empresas podem implantar a gestão da demanda.

Outra contribuição está associada aos indicadores de desempenho para a gestão da demanda. Alguns autores ressaltam a necessidade de uma estrutura de indicadores de desempenho (CROXTON et al., 2008; STOCK; BOYER; HARMON, 2010), mas não propõem quais indicadores as empresas poderiam utilizar para monitorar o processo de gestão da demanda. Além de apontar quais são os indicadores, esta pesquisa ressalta a necessidade da interação inter e intraempresas para acompanhá-los, como também o envolvimento da alta gerência em reuniões periódicas para acompanhar o desempenho das empresas. Desta forma, os executivos se sentem mais comprometidos em cumprir o que foi acordado.

Portanto, a implantação bem conduzida do processo de gestão da demanda pode melhorar o nível de serviço prestado ao cliente e gerar benefícios substanciais para os resultados financeiros da empresa. Para o setor atacadista, a disponibilidade de produtos é importante para garantir o atendimento ao cliente, porém os custos relacionados a estoque constituem o principal investimento do setor. Consequentemente, um controle efetivo dos estoques representa uma oportunidade para atingir um nível de serviço elevado, buscando equilibrar os custos (SYNTETOS et al., 2010).

Apesar de algumas etapas ou situações apresentadas neste estudo poderem ser generalizadas para outras cadeias de suprimentos, o estudo é limitado a um caso específico e a abrangência de qualquer conceito ou experiência citada deve ser estudada de forma mais ampla. Além disso, a amostra desta pesquisa pode ser considerada limitada, pois foi pesquisado apenas o segmento de produtos de mercearia básica e o relacionamento entre díades. Trabalhos futuros poderiam ser realizados, abrangendo:

- Um estudo semelhante que utilizasse como empresa focal uma grande rede de supermercados, ou que abrangesse um número maior de cadeias de suprimentos, ou que analisasse outros elos da cadeia de suprimentos;

- Um estudo semelhante em outros setores industriais para fins de análises comparativas;

- Um estudo quantitativo que permita validar o modelo de gestão da demanda proposto nesta pesquisa; e 
- Um estudo para avaliar o estágio de maturidade das empresas em relação à gestão da demanda na cadeia de suprimentos.

\section{Agradecimentos}

À CAPES pelo auxílio financeiro.

\section{Referências}

ADEBANJO, D. Understanding demand management challenges in intermediary food trading: a case study. Supply Chain Management, v. 14, n. 3, p. 224-233, 2009. http://dx.doi.org/10.1108/13598540910954566

ASSOCIATION FOR OPERATIONS MANAGEMENT - APICS. Sales and Operations Planning: the secret to world class supply chain. APICS, 2009. Apics dinner meeting. Disponível em: <http://www.apics-fraservalley.org/uploads/files/ Year0809/april2009PDM.pdf>. Acesso em: 29 dez. 2010.

BAILEY, K.; FRANCIS, M. Managing information flows for improved value chain performance. International Journal of Production Economics, v. 111, n. 1, p. 2-12, 2008. http://dx.doi.org/10.1016/j.ijpe.2006.11.017

BALJKO, J. L. Expert warns of 'bullwhip effect'. Eletronic Buyers' News, n. 1170, Jul. 1999.

BARRATT, M.; OLIVEIRA, A. Exploring the experiences of collaborative planning iniciatives. International Journal of Physical Distribution \& Logistics Management, v. 31, n. 4, p. 266-289, 2001. http:// dx.doi.org/10.1108/09600030110394932

BAUER, M. W. Análise de conteúdo clássica: uma revisão. In: BAUER, M. W.; GASKELL, G. (Eds.). Pesquisa qualitativa com texto, imagem e som. Petrópolis: Vozes, 2002. Manual prático.

BOWERSOX, D. J.; CLOSS, D. J.; STANK, T. P. How to master cross-enterprise collaboration. Supply Chain Management Review, v. 7, n. 4, p. 18-27, 2003.

CHEN, F. et al. The Bullwhip Effect: managerial insights on the impact of forecasting and information on variability in a supply chain. In: TAYUR, S.; GANESHAN, R.; MAGAZINE, M. Quantitative models for supply chain management. Norwell: Kluwer Academic Publishers, 2003.

CHEN, H.; DAUGHERTY, P. J.; ROATH, A. S. Defining and operationalizing supply chain process integration. Journal of Business Logistics, v. 30, n. 1, p. 63-84, 2009. http://dx.doi.org/10.1002/j.2158-1592.2009.tb00099.x

CLAASSEN, M. F. T.; VAN WEELE, A. F.; VAN RAAIJ, E. M. Performance outcomes and success factors of vendor managed inventory (VMI). Supply Chain Management: An International Journal, v. 13, n. 6, p. 406-414, 2008. http://dx.doi.org/10.1108/13598540810905660

CROXTON, K. L. et al. The Demand Management Process. In: LAMBERT, D. M. Supply Chain Management: Processes, Partnerships, Performance. Florida: Supply Chain Management Institute, 2008. p. 87-104.

DANESE, P. Designing CPFR collaborations: insights from seven case studies. International Journal of Operations \& Production Management, v. 27, n. 2, p. 181-204, 2007. http://dx.doi.org/10.1108/01443570710720612
ELLRAM, L. M.; EDIS, O. R. V. A case study of successful partnering implementation. International Journal of Purchasing and Materials Management, v. 32, n. 4, p. 20-28, 1996. http://dx.doi.org/10.1111/j.1745493X.1996.tb00227.x

ELVANDER, M. S.; SARPOLA, S.; MATTSSON, S. A. Framework for Characterizing the Design of VMI Systems. International Journal of Physical Distribution and Logistics Management, v. 37, n. 10, p. 782-798, 2007. http://dx.doi.org/10.1108/09600030710848914

ESPER, T. L. et al. Demand and supply integration: a conceptual framework of value creation through knowledge management. Academy of Marketing Science, v. 38, n. 1, 2010.

FAWCETT, S. E.; MAGNAN, G. M.; McCARTER, M. W. A three-stage implementation model for supply chain collaboration. Journal of Business Logistics, v. 29, n. 1, p. 93-112, 2008. http://dx.doi. org/10.1002/j.2158-1592.2008.tb00070.x

FIORIOLLI, J. C.; FOGLIATTO, F. S. Modelagem matemática do efeito chicote em ambientes com demanda e lead time estocásticos. Pesquisa Operacional, v. 29, n. 1, p. 129-151, jan./abr. 2009. http://dx.doi.org/10.1590/ S0101-74382009000100007

FLYNN, B. B.; HUO, B.; ZHAO, X. The impact of supply chain integration on performance: A contingency and configuration approach. Journal of Operations Management, v. 28, n. 1, p. 58-71, 2010. http://dx.doi. org/10.1016/j.jom.2009.06.001

FRENCH JUNIOR, J. P.; RAVEN, B. The bases of social power. In: CARTWRIGHT, D. (Ed.). Studies in social power. Ann Arbor: University of Michigan Press, 1959.

GEARY, S.; DISNEY, S. M.; TOWILL, D. R. On bullwhip in supply chains: historical review, present practice and expected future impact. International Journal of Production Economics, v. 101, n. 1, p. 2-18, 2006. http://dx.doi.org/10.1016/j.ijpe.2005.05.009

GIMENEZ, C. Logistics integration processes in the food industry. International Journal of Physical Distribution \& Logistics Management, v. 36, n. 3, p. 231-249, 2006. http://dx.doi.org/10.1108/09600030610661813

GOLICIC, S. L.; FOGGIN, J. H.; MENTZER, J. T. Relationship magnitude and its role in interorganizational relationship structure. Journal of Business Logistics, v. 24, n. 1, p. 57-75, 2003. http://dx.doi.org/10.1002/j.2158-1592.2003. tb00032.x

GRIMSON, J. A.; PYKE, D. F. Sales and operations planning: an exploratory study and framework. International Journal of Logistics Management, v. 18, n. 3, p. 322-346, 2007. http://dx.doi.org/10.1108/09574090710835093

HILLETOFTH, P.; ERICSSON, D. Demand chain management: next generation of logistics management. Conradi Research Review, v. 4, n. 2, p. 1-18, 2007.

HILLETOFTH, P.; ERICSSON, D.; CHRISTOPHER, M. Demand chain management: a Swedish industrial case study. Industrial Management and Data Systems, v. 109, n. 9, p. 1179-1196, 2009. http:// dx.doi.org/10.1108/02635570911002261

HOLWEG, M. et al. Supply chain collaboration: making sense of the strategy continuum. European Management 
Journal, v. 23, n. 2, p. 170-181, 2005. http://dx.doi. org/10.1016/j.emj.2005.02.008

HORVATH, L. Collaboration: the key to value creation in supply chain management. Supply Chain Management: An International Journal, v. 6, n. 5, p. 205-207, 2001. http://dx.doi.org/10.1108/EUM0000000006039

JÜTTNER, U.; CHRISTOPHER, M.; BAKER, S. Demand chain management-integrating marketing and supply chain management. Industrial Marketing Management, v. 36, p. 377-392, 2007. http://dx.doi.org/10.1016/j. indmarman.2005.10.003

KAIPIA, R.; KORHONEN, H.; HARTIALA, H. Planning nervousness in a demand supply network: an empirical study. International Journal of Logistics Management, v. 17, n. 1, p. 95-113, 2006. http://dx.doi. org/10.1108/09574090610663455

KING, N. Template analysis. In: SYMON, G.; CASSELL, C. (Eds.) Qualitative Methods and Analysis in Organizational Research: a Practical Guide. Thousand Oaks: Sage, 1998. p. 118-134.

LAMBERT, D. M. Supply Chain Management. In: LAMBERT, D. M. Supply Chain Management: Processes, Partnerships, Performance. Florida: Supply Chain Management Institute, 2008. p. 1-23.

LAPIDE, L. Sales and operations planning Part I: the process. The Journal of Business Forecasting, v. 23, n. 3, p. 17-20, 2004.

LAPIDE, L. Sales and operations planning Part III: a diagnostic model. The Journal of Business Forecasting, v. 24, n. 1, p. 13-16, 2005.

LARSEN, T. S.; THERNOE, C.; ANDRESEN, C. Supply chain collaboration: theoretical perspective and empirical evidence. International Journal of Physical Distribution \& Logistics Management, v. 33, n. 6, p. 531-49, 2003. http://dx.doi.org/10.1108/09600030310492788

LEE, H.; PADMANABAHN, V.; WHANG, S. Information distortion in a supply chain: the bullwhip effect. Management Science, v. 43, n. 4, p. 546-558, 1997. http://dx.doi.org/10.1287/mnsc.43.4.546

LEJEUNE, M. A.; YAKOVA, N. On characterizing the 4 C's in supply chain management. Journal of Operations Management, v. 23, n. 1, p. 81-100, 2005. http://dx.doi. org/10.1016/j.jom.2004.09.004

MANGINI, E. R.; MOORI, R. G.; PERERA, L. C. J. Uma Análise Investigativa do 'Efeito Chicote' na Cadeia de Suprimentos da Indústria Alimentícia. In: ENCONTRO NACIONAL DA ASSOCIAÇÃO NACIONAL DE PÓS-GRADUAÇÃO E PESQUISA EM ADMINISTRAÇÃO - ANPAD, 31., 2007, Rio de Janeiro. Anais... Rio de Janeiro: ENANPAD, 2007.

McCARTHY, T. M.; GOLICIC, S. L. Implementing collaborative forecasting to improve supply chain performance. International Journal of Physical Distribution \& Logistics Management, v. 32, n. 6, p. 431-454, 2002. http://dx.doi.org/10.1108/09600030210437960

McLAREN, T.; HEAD, M.; YUAN, Y. Supply chain collaboration alternatives: understanding the expected cost and benefits. Internet Research: Electronic Networking Applications and Policy, v. 12, n. 4, p. 348-364, 2002. http://dx.doi.org/10.1108/10662240210438416
MELO, D. C.; ALCANTARA, R. L. C. Gestão da Demanda sob a perspectiva da gestão da cadeia de suprimentos: uma abordagem além da previsão. In: ENCONTRO NACIONAL DE ENGENHARIA DE PRODUÇÃO - ENEGEP, 29., 2009, Salvador. Anais... Salvador: ABEPRO, 2009.

MELO, D. C.; ALCANTARA, R. L. C. Proposição de uma Abordagem Conceitual para a Gestão da Demanda em Cadeias de Suprimentos. In: ENCONTRO DA ASSOCIAÇÃO NACIONAL DE PÓS-GRADUAÇÃO E PESQUISA EM ADMINISTRAÇÃO - ENANPAD, 34., 2010, Rio de Janeiro. Anais... Rio de Janeiro: ANPAD, 2010.

MENTZER, J. T.; FONGHIN, J. H.; GOLICIC, S. L. Supply chain collaboration: enablers, impediments and benefits. Supply Chain Management Review, v. 4, Sept./Oct. 2000.

MENTZER, J. T. et al. Defining supply chain management. Journal of Business Logistics, v. 22, n. 2, p. 1-25, 2001. http://dx.doi.org/10.1002/j.2158-1592.2001.tb00001.x

MENTZER, J. T.; MOON, M. A. Sales forecasting management: a demand management approach. Thousand Oaks: Sage, 2005.

MENTZER, J. T. et al. Demand Management. In: MENTZER, J. T.; MYERS, M. B.; STANK, T. P. Handbook of Global Supply Chain Management. Thousand Oaks: Sage, 2007. http://dx.doi.org/10.4135/9781412976169.n5

MEUNIER-FITZHUGH, K. L.; PIERCY, N. F. Exploring collaboration between sales and marketing. European Journal of Marketing, v. 41, n. 7-8, 2007, p. 939-955. http://dx.doi.org/10.1108/03090560710752465

MIN, S. et al. Supply chain collaboration: what's happening? The International Journal of Logistics Management, v. 16, n. 2, p. 237-256, 2005. http:// dx.doi.org/10.1108/09574090510634539

MOURITSEN, J.; SKJOTT-LARSEN, T.; KOTZAB, H. Exploring the contours of supply chain management. Integrated Manufacturing Systems, v. 14, n. 8, p. 686-695, 2003. http://dx.doi.org/10.1108/09576060310503483

PAIK, S. K.; BAGCHI, P. K. Understanding the causes of the bullwhip effect in a supply chain. International Journal of Retail and Distribution Management, v. 35, n. 4, p. 308-324, 2007. http://dx.doi. org/10.1108/09590550710736229

PIRES, S. R. I. Gestão da cadeia de suprimentos: conceitos, estratégias, práticas e casos. São Paulo: Atlas, 2009.

RAINBIRD, M. Demand and supply chains: the value catalyst. International Journal of Physical Distribution and Logistics Management, v. 34, n. 3-4, 2004.

RANKING ABAD/NIELSEN. 391 Maiores empresas do atacado distribuidor. Revista Distribuição, v. 208, n. 18 , maio 2010.

SABATH, R. E.; FONTANELLA, J. The unfulfilled promise of supply chain collaboration. Supply Chain Management Review, v. 6, n. 4, p. 24-29, 2002.

SEIFERT, D. Collaborative plannning, forcasting and replenishment: how to create a supply chain advantage. New York: AMACOM, 2003.

SIMATUPANG, T. M.; SRIDHARAN, R. Benchmarking supply chain collaboration: an empirical study. Benchmarking: An International Journal, v. 11, n. 5, p. $484-503,2004$. 
SIMATUPANG, T. M.; SRIDHARAN, R. The collaborative supply chain. The International Journal of Logistics Management, v. 13, n. 1, p. 15-30, 2002. http://dx.doi. org/10.1108/09574090210806333

SPEKMAN, R. E.; SALMOND, D. J.; LAMBE, C. J. Consensus and collaboration: norm-regulated behaviour in industrial marketing relationships. European Journal of Marketing, v. 31, n. 11-12, p. 832-856, 1997. http:// dx.doi.org/10.1108/03090569710190569

SRIRAM, V.; KRAPFEL, R.; SPEKMAN, R. E. Antecedents to buyer-seller collaboration: an analysis from the buyer's perspective. Journal of Business Research, v. 25, n. 4, p. 303-320, 1992. http://dx.doi. org/10.1016/0148-2963(92)90026-8

STANK, T. P.; DAUGHERTY, P. J.; AUTRY, C. W. Collaborative planning, supporting automatic replenishment programs. Supply Chain Management, v. 4, n. 2, p. 75-85, 1999. http://dx.doi.org/10.1108/13598549910264752

STANK, T. P.; KELLER, S. B.; DAUGHERTY, P. J. Supply chain collaboration and logistical service performance. Journal of Business Logistics, v. 22, n. 1, p. 29-48, 2001. http://dx.doi.org/10.1002/j.2158-1592.2001.tb00158.x

STOCK, J. R.; BOYER, S. L.; HARMON, T. Research opportunities in supply chain management. Journal of the Academy of Marketing Science, v. 38, p. 32-41, 2010. http://dx.doi.org/10.1007/s11747-009-0136-2

SYNTETOS, A. A. et al. Forecasting and stock control: a study in a wholesaling context. International Journal of Production Economics, v. 127, p. 103-111, 2010. http://dx.doi.org/10.1016/j.ijpe.2010.05.001

TAYLOR, D. H. Demand amplification has it got us beat? International Journal of Physical Distribution and Logistics Management, v. 30, n. 6, p. 515-533, 2000. http://dx.doi.org/10.1108/09600030010372630

TAYLOR, D. H.; FEARNE, A. Towards a framework for improvement in the management of demand in agri-food supply chains. Supply Chain Management: An International Journal, v. 11, n. 5, 2006.

TAYLOR, D. H. Demand management in agri-food supply chains: an analysis of the characteristics and problems and a framework for improvement. The International Journal of Logistics Management, v. 17, n. 2, p. 163-186, 2006. http://dx.doi.org/10.1108/09574090610689943

TROQUE, W. A. Influência das práticas da gestão da cadeia de suprimentos sobre a gestão da demanda: Um Modelo de Análise Conceitual. 2003. 189 f. Dissertação (Mestrado em Engenharia de Produção)-Faculdade de
Engenharia, Arquitetura e Urbanismo, Universidade Metodista de Piracicaba, Santa Bárbara D’Oeste, 2003.

TUOMINEN, M. Channel collaboration and firm value proposition. International Journal of Retail \& Distribution Management, v. 32, n. 4, p. 178-189, 2004. http://dx.doi.org/10.1108/09590550410528953

VAN HOEK, R. I.; MITCHELL, A. J. The challenge of internal misalignment. International Journal of Logistics: Research and Applications, v. 9, n. 3, p. 269-281, 2006.

VIEIRA, J.; YOSHIZAKI, H.; HO, L. Collaboration intensity in the Brazilian supermarket retail chain. Supply Chain Management: an international Journal, v. 14, n. 1, p. 11-21, 2009.

VIVALDINI, M.; SOUZA, F. B.; PIRES, S. R. I. Implementação de um sistema Collaborative Planning, Forecasting, and Replenishment em uma grande rede de fast food por meio de um prestador de serviços logísticos. Gestão \& Produção, v. 15, n. 3, p. 477-489, set./dez. 2008. http://dx.doi.org/10.1590/S0104-530X2008000300005

VOLLMANN, T. E. et al. Manufacturing Planning and Control for Supply Chain Management. Boston: McGraw-Hill, 2004.

VOLUNTARY INTERINDUSTRY COMMERCE STANDARDS - VICS. Collaborative Planning, Forecasting and Replenishment (CPFR ${ }^{\circledR}$ ): an overview 2004. VICS, 2004. Disponível em: <http:// www.vics.org/docs/guidelines/CPFR_Overview_US-A4. pdf> Acesso em: 22 dez. 2010.

VOLUNTARY INTERINDUSTRY COMMERCE SOLUTIONS - VICS. Linking CPFR and S\&OP: A Roadmap to Integrated Business Planning. 2010. Disponível em: <http://www.vics.org/docs/committees/ cpfr/CPFR_SOP_Guideline_Ver1.0Sep2010.pdf $>$ Acesso em: 29 dez. 2010.

WALLACE, T. F. Sales \& Operations Planning: the how-to handbook. Cincinnati: T. F. Wallace \& Company, 2004.

WALTERS, D. Demand chain effectiveness supply chain efficiencies. Journal of Enterprise Information Management, v. 19, n. 3, p. 246-261, 2006. http:// dx.doi.org/10.1108/17410390610658441

WALTERS, D.; RAINBIRD, M. The Demand Chain as an Integral Component of the Value Chain. Journal of Consumer Marketing, v. 21, n. 7, p. 465-475, 2004. http://dx.doi.org/10.1108/07363760410568680

YIN, R. K. Estudo de caso: planejamento e métodos. Porto Alegre: Bookman, 2005. 
